\title{
Development of an integrated method to determine, present and manage flood risk in flood plains
}

\author{
C. Küpferle ${ }^{1}$, S. Kräßig ${ }^{1} \&$ T. Hirschhäuser ${ }^{2}$ \\ ${ }^{1}$ Golder Associates Hamburg, \\ Hydraulic Engineering and Flood Management Team, Germany \\ ${ }^{2}$ State Agency for Nature and Environment Schleswig-Holstein, \\ Dept. of Hydrology, Germany
}

\begin{abstract}
Due to the worldwide increasing threats of flooding as a consequence of climate change and the greater use by humans of natural floodplains, a change of paradigm from flood protection to integrated flood risk management (FRM) has taken place in Europe. This is reflected in the EU Flood Directive and in the German Act to Improve Preventive Flood Control. To fulfil these new legal requirements following an integrated flood risk assessment, the application and results of water management tools need to be accessible during spatial planning processes. The effects of land use management may negatively influence the flood risk potential in a certain area. Therefore decision makers need to quantify the cause and consequences relationship of their design.

The first part of this paper describes the derivation of flood risk, using hydrological and hydraulic models and the simple and understandable visualization of the results in flood risk maps. The second part of the paper uses this methodology and links the models and results directly into the land use planning process through a Decision Support System (DSS).

Keywords: flood risk maps, land use planning, urban catchments, EU flood directive, risk awareness, economical damage, DSS, spatial planning, modelling, inundation areas, flood risk management, GIS, flood risk.
\end{abstract}




\section{Introduction}

The change of paradigm in current FRM strategies is legally reflected in Germany in the new national Act to Improve Preventive Flood Control and by the EU Flood Directive on a European level. The idea of living with floods as opposed to fighting against floods has finally been integrated into the legal system. Planners and engineers have realized that flood protection measures cannot be the only way to handle the risk of flooding. Managing floods is much more sustainable then building large protection structures. The new FRM strategy must include stakeholder engagement, targeted flood risk information, climate change effects, land use planning, etc. when addressing flooding issues. The described procedure determines inundation areas, with a subsequent monetary assessment of the expected flood risk in these areas. The involvement of stakeholders as well as the much-needed capacity building activities within the discipline of spatial planning has been identified as the next logical step towards sustainable FRM.

\section{Determination of flood risk}

According to the scientific predictions of the IPCC-Report [1] the climate of the earth will change within the next decades. As a possible consequence sea levels will rise. Many countries nowadays are using large areas of land for settlement and agriculture that have been flooded regularly in past years. With increasing need for land, the probability of flood disasters will increase. Therefore politicians and planners, particularly from lowland areas, are being forced to improve their strategies for sustainable flood management. These strategies should include providing decision makers and stakeholders with more and better information on flood risk.

\subsection{Legal foundations and consequences}

Between 1998 and 2004 Europe suffered more then 100 flood events, which caused 700 deaths and an insured economic damage of $€ 25$ billion [2]. In response to this a new German Water Act to Improve Preventive Flood Control [3] and the European Flood Directive on the assessment and management of flood risks [4] entered into force over the past three years. Both instruments aim for sustainable flood management as their key objective. Regarding the increasing urbanisation in natural flood plains and effects of climate change the focus is shifting now from damage-prevention to damage-avoidance.

Effective river management includes measures to reduce flood damage. This demands both a detailed overview of the existing flood situation and prognoses of anthropogenic and natural changes in the river catchment. Furthermore, the legal framework requires the determination of flood plains for different statistical return periods. Measured time-series at gauging stations often lack the historic datasets needed for such a statistical analysis. Therefore flood analysis demands the use of hydrological, hydraulic and socio-economic models. 


\subsection{Procedures for sustainable flood risk modelling}

When designing water management models, a detailed dataset of topography and hydrometeorology covering the whole river catchment is one of the main requirements. Remote sensing has become state of the art and provides elevation information up to 10 centimetres accuracy for surface areas without vegetation [5]. Looking at the availability of hydrometeorological data in Europe, more than 20.000 operational gauging stations covered all major river basins in 1994 [6]. In combination with the existing mesh of recording rain gauges and progress in weather-radar systems, the input data set for water management models is sufficiently accurate.

With the wide range of different modelling systems user experience is essential to obtain reliable results and to decide on the best fitting model concept to fulfil legal boundary conditions. In defining flood risk as the product of probability of occurrence and vulnerability, it is not enough to only determine inundation areas but an elaborate potential damage assessment is also required.

\subsubsection{Workflow}

A flood risk assessment starts with the determination of design discharges, applying rainfall-runoff-models or flood frequency analysis. These calculated hydrographs for different return periods serve as boundary conditions for one or two-dimensional hydraulic models to determine corresponding water levels in river sections. One-dimensional models calculate water levels only in each river cross section and consequently need the intersection of water levels with a digital terrain models to determine inundation areas. In contrast, from two-dimensional models the inundation areas can be directly derived since the flow fields are simulated in the whole the flood plain. The next step is to calculate the potential flood damage, depending on land vulnerability. Regarding economic costs, a damage assessment using a micro-scale approach (based on existing object damage), cannot be implemented for whole river basins. Therefore a meso-scale approach is the optimal tool [7] to link economic damage to land use types. Lots of experience in applying these procedures exists for the rivers Rhine [8] and Elbe [9] in Germany.

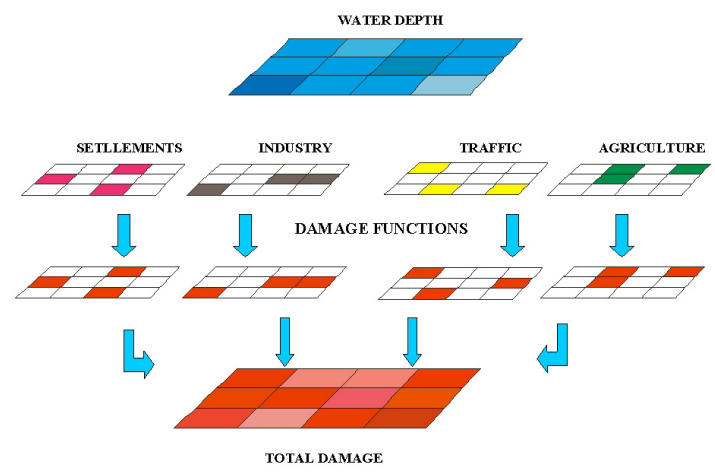

Figure 1: $\quad$ Approach for damage assessment [10]. 
Spatial distributions of land use and regional statistical data on asset values are the basis for the suggested meso-scale approach. Using depth damage curves and hydraulic input data, a relative damage potential per unit area can be calculated. Grid orientated processing provides an efficient calculation [10] of the damage potentials. Figure 1 shows this procedure graphically.

\subsubsection{Results}

Steps one and two of a flood risk assessment, as mentioned in Section 2.2.1, result in inundation maps (Figure 2). The main idea of the European and German flood regulations is to improve preventive flood control through informing affected people and raising their awareness of the existing flood risk situation. For this, inundation and flood damage maps are not sufficient because stakeholders may misunderstand the cartographic results, as they do not have the professional background to read them properly. One possible solution to this dilemma is to assign the monetary flood damage to non-monetary flood categories. These categories are defined as different levels of concern to better communicate flood risk to stakeholders; these categories are comparable to the existing definition of flood risk zones.

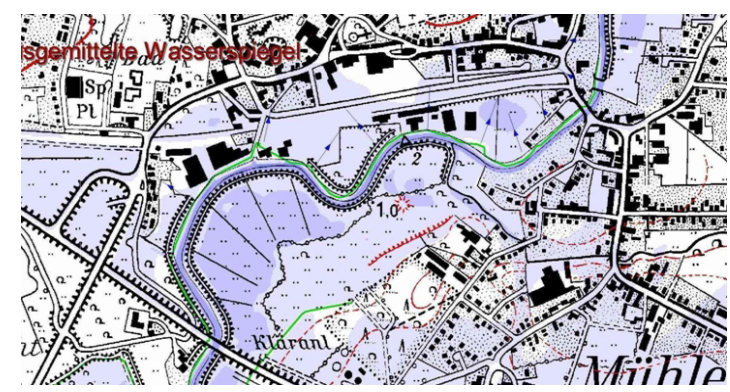

Figure 2: $\quad$ Inundation map [11].

\section{Flood risk mapping and presentation}

By definition probability is linked to flood risk, and therefore all likely flood events in which damage can occur must be considered for a damage assessment. The annual specific damage takes into account the return periods of all significant flood events (Figure 3). Classifying annual damage potentials allows the classification of different level of concern. The necessary threshold values are calculated using a cost comparison method on the basis of the annual costs of a typical privately used house in an urban area [12]. Comparing the annual cost of operation and capital with the annual damage, three levels can be defined: moderate, medium and high concern. The criterion for determining the boundaries between levels is the realistic possibility of stakeholders making financial provisions to cover damage to their property caused by a flood event.

The damage potential differs considerably between agricultural land use and settlements. Thresholds for farming and grassland can be defined by multiplying 
a reasonable inundation probability with the value of annual crop yield. For presenting the zones of different levels of concern a simple legend, like a traffic light, helps laymen to understand flood risk maps.

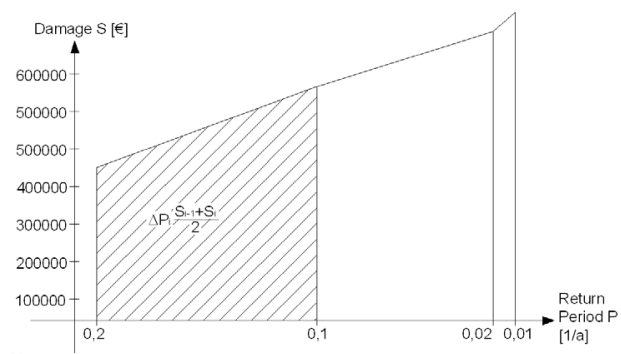

Figure 3: Annual damage [12].

\section{Flood risk management (FRM)}

The EU Flood Directive [4] introduces a new flood risk management tool, the flood risk management plan (FRMP). The input to this plan is provided by applying the methodology described in the previous sections. Member States must ensure that these flood risk management plans are completed and published by $22^{\text {nd }}$ of December 2015 .

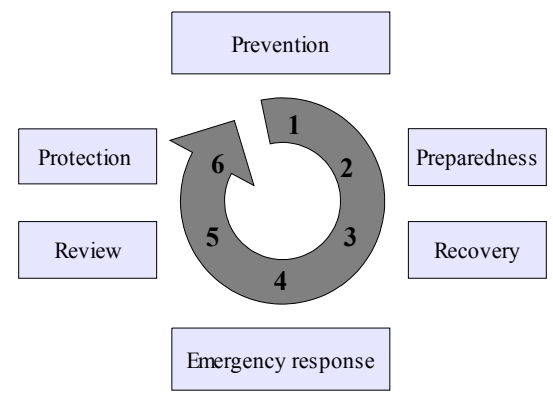

Figure 4: $\quad$ Flood risk management cycle [4].

Additionally, authorities are obliged to involve all relevant stakeholders (incl. the public) during this process. One of the major components of this plan is a set of objectives and appropriate measures to reduce the risk of flooding in a particular river basin, following the management cycle shown in Figure 4.

Floods are natural phenomena that cannot be prevented. However, some human activities (e.g. increasing human settlements and economic assets in floodplains, reduction of the natural water retention by change of land use, etc.) and climate change can contribute to an increasing frequency and possibly to increased adverse impacts of flood events within a catchment. The available space must be managed wisely, especially in densely populated areas where 
high-value properties can be at risk during floods. The EU Initiative ERA-NET Crue [13] has recently identified the integration of spatial planning and FRM as a major research topic for the future. Already, in 2006, the European funded project FLOWS (Flood Plain Land-use Optimizing Sustainability, www.flows.nu) addressed these issues and developed a basic concept of a Decision Support System for spatial planners (DSS-SP).

\subsection{Interlinking spatial planning and flood risk management}

Planning is a complex, iterative and highly dynamic process with many different stakeholder interests. When talking about linking spatial planning with FRM we are implying a multi-disciplinary decision process. The ideal goal for a planner is to find the most acceptable development schema, balancing all relevant socioeconomic and environmental factors within the planning area. This directly influences how and when stakeholder interests need to be integrated in the planning process. The planner must have a direct representation of cause and consequence relationships during the design phase [15]. This relationship can be visualized and presented to land use planners, using hydrological and hydraulic models within a DSS [16].

\subsubsection{Conceptional approach}

Each planning activity within a spatial context consists of two different processes, the processing of technical information and the process of political consensus building. They may be separated heuristically but not really in an empirical [14] sense, because they depend strongly on each other. The system proposed in this paper supports the decision making process for spatial planning through the FRM. The main focus is on the daily working routine of a land use planner (local planner) and therefore only covers the technical planning process. The general steps describing this process are shown in Figure 5 (left side). This logical schema serves as a conceptional guide for how and where a FRM can be integrated in a DSS for spatial planners.

Focusing on the technical aspects of land use planning, and linking them to the necessary steps for an FRM, levels three and four in Figure 5 are the core activities to be integrated into a DSS.

The planning process can be split into two phases, the scoping phase and the actual planning phase. For the scoping phase, the planner ideally needs to consider all stakeholder interests in the new development. This phase can be supported by an intelligent (automatic) data mining algorithm. All digitally available data (the data must be available as a GIS data base/web-service (e.g. ArcSDE, Oracle, Web Feature Service)) is processed and evaluated against a (predefined) conflict matrix. The result of this operation is a map with potentially conflicting stakeholder interests (e.g. flood risk, inundation areas, waste sites, biotopes, groundwater recharge zones, etc.), ranked according their severity (level 1 to 5).

After the scoping, the planner will have defined the potential area suitable for the new development as a polygon. The polygon is the basis for a more detailed 


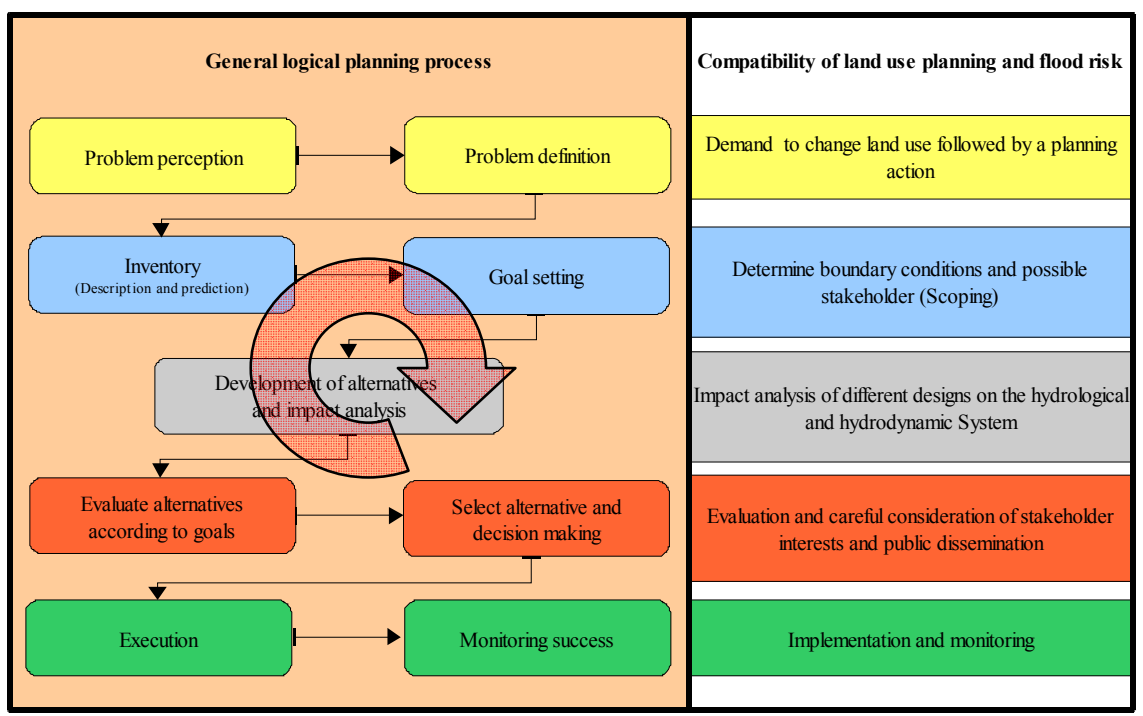

Figure 5: $\quad$ Planning schema.

land use design (e.g. industrial area, semi-detached housing, green areas, etc.), where each partial area is ascribed a sealing factor related to the type of land use.

\subsection{Evaluating the impact of land use planning on flood risk}

The effect of spatial and land use planning on the hydrological cycle in connection with a possible impact on flood risk can be simply reduced to two main parameters: the percentage of sealed surfaces and the type of land use in a newly-developed or planned development area. Changing these parameters within the catchment will alter the drainage capability and therefore the discharge balance in this section of the river. These processes can be calculated in great detail with today's mathematical models and methods, e.g. rainfall runoff models and hydraulic models. These models are the basis for the DSS-SP, and the planner can compensate for the effects of land-use changes by applying measures like retention basins, reduction of sealed surfaces or local sustainable urban drainage systems (SUDS). These measures are simplified and automatically inserted into the existing models. Comparing status quo results with scenario simulations will enable the effect on the water cycle of a specific land use change to be quantified. By minimizing the negative effects the planner can optimize his design.

\section{Examples}

\subsection{Flood risk mapping in northern Germany}

The state of Schleswig-Holstein, in the northern part of Germany, published a guideline for Inland flood protection and retention in September 2007. 
According to the new flood acts, the flood protection strategy of SchleswigHolstein is considered in flood precaution, flood-adapted land-use management and technical flood protection [11].

Determination of flood plains and clear statements on flood risk are key elements of the sustainable flood management pursued by the state government. Besides inundation maps, flood risk maps are also published. Flood risk is calculated as mentioned in Section 3.

Thresholds for urban land use are values of $0.1 € / \mathrm{m}^{2}$ and $1.0 € / \mathrm{m}^{2}$, to classify in zones of moderate, medium and high level of concern. The cost comparison method is carried out for a representative private settlement area of $1.000 \mathrm{~m}^{2}$. Agricultural areas are divided by a limit of $0.01 € / \mathrm{m}^{2}$ into zones of low and medium level of concern. In Figure 6 an example is presented of flood risk based on this government standard.

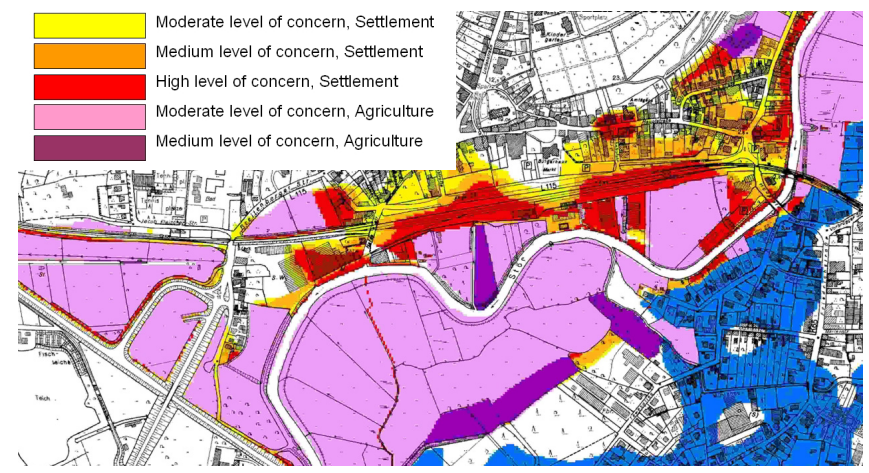

Figure 6: $\quad$ Flood risk map [11].

\subsection{Urban land use planning in the city of Hamburg}

The conflict analysis will be used as an example of how the DSS works and interacts with the planning procedure described in Figure 5. The schema in Figure 7 is used to show the conflict analysis for scoping in the first planning phase. The GIS-data are expected to be accessible via the Internet, as an OGC (Open Geospatial Consortium (www.opengeospatial.org)) web-service, where each stakeholder interest is represented as a separate GIS-layer with a set of rules defining the potential conflicts (intensity) between each interest and a specific land-use.

$$
B_{G, k}=\sum_{i=1}^{N} X_{i} \cdot I_{N Z}=\sum_{i=1}^{N} \frac{A_{i}}{A_{P G}} \cdot I_{N Z}
$$

$\mathrm{B}_{\mathrm{G}, \mathrm{k}}=$ total potential conflict of design $\mathrm{k}$

$\mathrm{N}=$ Number of affected partial areas

$\mathrm{A}_{\mathrm{i}}=\mathrm{i}^{\text {th }}$ affected area

$\mathrm{A}_{\mathrm{PG}}=$ Plan area

$\mathrm{NZ}=$ intensity of conflict for each land use type 


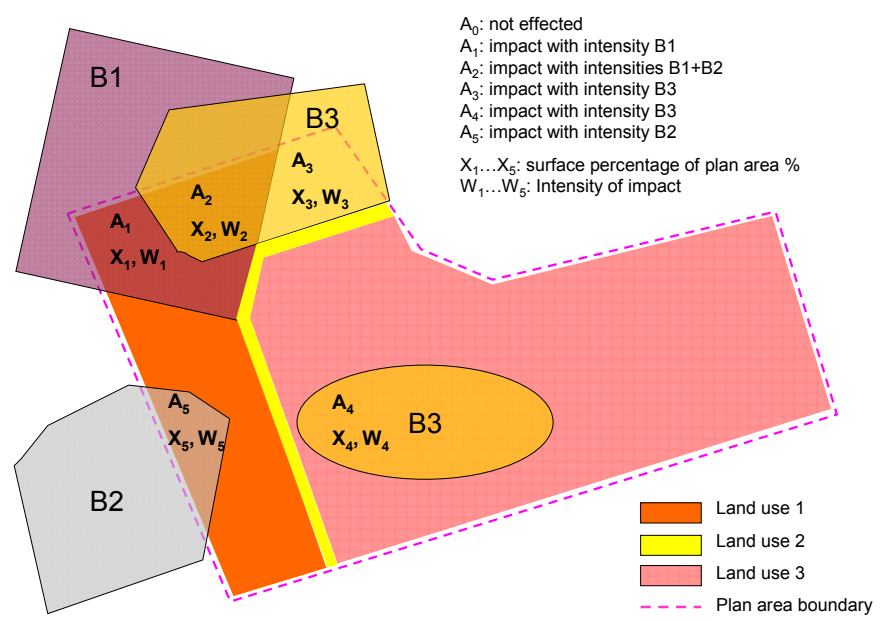

Figure 7: Scoping phase: impact assessment of the planning area on stakeholder interests.

With intersecting land use geometries B1 to B3 with the plan area $\mathrm{A}_{\mathrm{PG}}$ and consecutively applying equation (1) it is possible to calculate area-weighted total potential conflict intensity. This type of information will be an input to a MCA (Multi-Criteria-Analysis), in which different designs will be ranked according their conflict intensity, effect on flooding, etc., to help the planner find the best solution.

\section{Conclusion}

The DSS with the integrated models has been successfully applied in an urban catchment, namely the City of Hamburg. Currently the system is being transferred from a pilot application to the standard procedural tool for urban land-use management. Besides using flood risk maps in the scoping phase the data on monetary flood damage can be used to optimize scenarios in the land-use planning phase as an input to cost-benefit analysis.

Further development and research potential exists in the required integration of objectives, as stated in the EU Flood Directive and the EU Water Framework Directive. The cause and consequence analysis must ideally be conducted for each stakeholder interest when setting up a river basin management plan, i.e. not only for spatial planning and flood risk issues.

\section{References}

[1] Intergovernmental Panel on Climate Change (IPCC) (Hg.). Fourth Assessment Report Climate Change 2007: Synthesis Report, 2007 
[2] European Flood Report 2005 - Central and Eastern Europe, Guy Carpenter and Company Ltd., 2005.

[3] Water Act to Improve Flood Control, The Federal Ministry for the Environment, Nature Conservation and Nuclear Safety, Federal Law Gazette I of 9 May 2005 page 1224, 2005.

[4] Directive 2007/60/EC of the European parliament and of the council of 23 October 2007on the assessment and management of flood risks, Official Journal of the European Union, 2007.

[5] R Katzenbeißer, S Kurz, Airborne Laserscanning, Photogrammetrie Fernerkundung Geoinformation, Journal 3, 2004.

[6] Hydrological Networks for Integrated and Sustainable Water Resources Management, International Workshop, Bundesanstalt für Gewässerkunde, Koblenz, 2003.

[7] Pasche E. From Fighting against Flood to Living with FloodINternational symposium on sustainable Flood Management of Korea, Korea, 2006.

[8] Atlas on the risk of flooding and potential damage due to extreme floods of the Rhine, International Commission fort he Protection of the Rhine, 2001

[9] Action Plan for the Flood Protection in the Elbe River Basin, International Commission for the Protection of the Elbe River, 2003

[10] Kräßig K., Development of an Integrated Method to Determine and Visualize Flood Risk in Flood Prone Areas, Hamburger Wasserbauschriften, 2007

[11] Inland flood protection and retention, Ministry of agriculture, environment and rural areas the State of Schleswig-Holstein, 2007

[12] Ökonomische Bewertung von Hochwasserschutzwirkungen, German Association for Water, Wastewater and Waste, Journal 10, 1985

[13] Karin De Bruijn et al., Inventory and Analysis of European Research needs on Flood Risk Management, CRUE Report, 2008

[14] D. Fürst, F. Scholles, Handbuch Therorien + Methoden der Raum- und Umweltplanung, Dortmunder Verlag für Bau- und Planungsliteratur, Dortmund 2001

[15] C. Köster, K. Krause, C. Küpferle, O. Simon, Ergebnisbericht des Workshops FLOWS, TU Hamburg-Harburg -Arbeitsbereich Stadt-, Regional- und Umweltplanung 1.05, 2004, Hamburg (unpublished)

[16] E. Pasche, C. Küpferle, N. Manojlovic, Capacity Building of Spatial Planners for Flood Risk Management in Urban Environment through Decision Support Systems and Interactive Learning, International Symposium on New Directions in Urban Water Management (UNESCO), 2007, Paris 